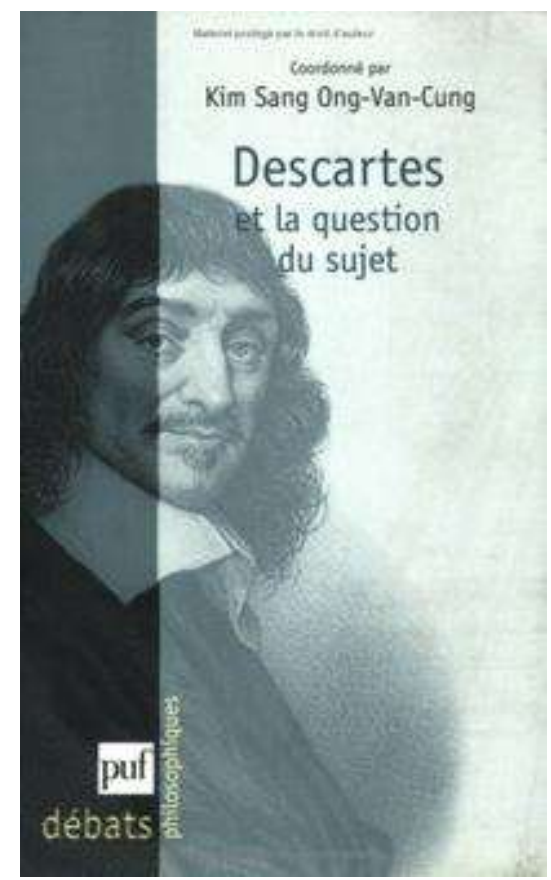

RESENHA: CANZIANI, Guido. "La métaphysique et la vie. Le sujet psychosomatique chez Descartes". IN: Kim Sang Ong-Van-Cung Descartes et la question du sujet. Paris: Presses Universitaires de France, 1999. 168p.

\title{
La métaphysique et la vie. Le sujet psychosomatique chez Descartes
}

\section{EDGARD VINÍCIUS CACHO ZANETTE ${ }^{1}$}

Nesta resenha exporemos a noção de sujet psychosomatique (sujeito psicosomático) em Descartes, conforme a interpretação de Guido Canziani². A união substancial apresenta problemas filosóficos densos e complexos, os quais incitam debates até os dias atuais. A distinção real entre a alma e o corpo de um homem é pensada, enquanto que o âmbito da união substancial remete ao reino do sentimento. Entre o pensável e o sentir, a filosofia de Descartes atravessa um percurso diacrônico entre duas instâncias fundamentais: de um lado a metafísica ou filosofia primeira expõe o âmbito essencial ou dos fundamentos. Nela a ordem do ser e do conhecer é rigorosamente investigada. Por outro lado, "há um nível mais complexo e confuso, inconcebível sem o primeiro, onde nossa vida se coloca, e onde se constrói a experiência concreta e individual pela qual cada um é isto que ele é" (CANZIANI, 1999, p. 68). Diante deste percurso diacrônico, o intérprete trata da instituição da noção de subjetividade, considerando estas duas figuras, em que a dimensão metafísica possibilita a investigação da natureza do ser concreto, sendo que na última

\footnotetext{
${ }^{1}$ Professor Doutor do Departamento de Filosofia da UERR [Universidade Estadual de Roraima] e exacadêmico bolsista do PET/Filosofia da UNIOESTE. E-mail: edgardzanette1@gmail.com

${ }^{2}$ Guido Canziani é professor da Universidade de Milão.
} 
é "onde a subjetividade se estabelece na união substancial da alma e do corpo" (Ibidem, p. 68).

Ao tratar, primeiramente, sobre a Metafísica, o autor mostra a dificuldade de a princesa Elisabeth conceber a ação recíproca entre a alma e o corpo a partir da distinção das substâncias (Cf. Ibidem, p. 68. n.1/Carta de Elisabeth à Descartes - o6 de 16 maio de 1643, AT III, p. 661). Na Metafísica o sujeito pensante constata sua própria existência. Nesta situação de descoberta de si mesmo como ego cogitans, por meio da via da análise o ego toma ciência que:

Que [o enganador muito poderoso] me engane quanto queira, ele não poderia jamais fazer com que eu nada seja, enquanto eu pensar ser alguma coisa [...] enfim posso concluir, e ter por constante que esta proposição: $E u$ sou, eu existo, é necessariamente verdadeira, todas as vezes que a pronuncio ou a concebo em meu espírito (DESCARTES, Meditações, II, AT, IX-1, p. 21).

Por sua vez a versão francesa dos Princípios resumiu de outra forma essa tomada de consciência de si mesmo: "Nós somos apenas porque nós pensamos". (Cf. Ibidem, p. 68 - 69. n.2/ DESCARTES. Princípios da Filosofia, I, 8, At, IX-2, p.28). Conforme Canziani explica (Cf. Ibidem, p. 70, n. 2), a proposição do cogito é anunciada na IV parte do Discurso do Método pela expressão seguinte: "Eu conheço [...] que sou uma substância porquê toda minha essência ou natureza não é senão pensar" (DESCARTES, AT, VI, p. 33).

Se a via da análise mostra a "verdadeira via pela qual uma coisa é metodicamente inventada" (DESCARTES, Segundas Respostas, AT, IX-1, p. 121), o eu pensante aparece como um "pensamento pensante", tal que o ego seria, até então, uma coisa abstrata, um puro pensamento com a função ou essência de pensar.

Esse esvaziamento da experiência individual para um outro, abstrato, norteado pela questão de saber como este ser se conhece como puro pensamento, isto remete a entender como ele estaria reduzido a se conhecer como por suas capacidades de ter conteúdos de pensamento, sendo uma coisa puramente pensante. Esta retirada do âmbito da experiência e a entrada em cena de uma filosofia da consciência, de uma verdade "inteiramente indubitável", própria ao cogito, ela não é assentada em um vazio de significado, ou mesmo em uma suposta superação da tradicional noção de subjectum, mas está posta sob o terreno do pensamento ser um sujeito que se põe ao se pensar, tal que:

[...] em nome da distinção tradicional entre o subjectum e suas faculdades, Descartes considera que é legítimo designar o sujeito do Cogito pelas palavras: <<esprit/espírito >>, <<âme/alma >>, $<<$ entendement/entendimento $>>$, ou $<<$ razão $>>$, porque $\mathrm{o}$ entendimento de que ele fala não é uma $<<$ faculdade $>>$ inerente a um subjectum eventual, mas $<<$ a coisa mesma que entende $>>$ (Cf. 
Terceiras Objeções, II, Resposta., AT, IX-1, p. 134 e p. 21), ou ainda, esta coisa que, primeiramente, começa a duvidar, e, duvidando, a se desdobrar por si, e a reencontrar passo a passo seu conhecimento a partir da identidade ontológica que ele pode se atribuir desde que ele descubra sua existência inegável (CANZIANI, 1999, p. 71).

Essa temática da noção de substancialidade como desdobramento da discussão com Hobbes nas Terceiras Objeções e Respostas parece justificar a história da filosofia que assenta em Descartes o mérito de inaugurar uma modernidade da subjetividade contra a objetividade reinante até então. O intérprete segue essa linha de raciocínio para mostrar como se articula a variedade de $<<$ modos $>>$ ou $<<$ maneiras $>>$ de pensar do ego tal que aí a substância/subjectum está dada. Isto porque o ego seria o sujeito da cogitatio, de "todos os atos pelos quais a mens (mente) se exprime, ele se afirma e se reconhece neles, e eles seriam inconcebíveis e indivisíveis sem ele (CANZIANI, 1999, p. 72).

Sujeito/subjectum, a teoria cartesiana da subjetividade trataria de abandonar uma experiência pré-reflexiva, de forma a liberar o sujeito de tudo o que lhe particularizava. Assim, sua biografia, sua memória, e as vivências de um contexto próprio ao vivido de sua unidade psicossomática, isto é deixado para trás, de forma que:

A Meditatio (Meditação) se estabelece pela via mais direta e irredutível de um tal princípio metafísico que sustenta, de maneira evidente, a individualidade da substância. O ego cogitans (eu pensante) significa, deste modo, a universalidade originária do espírito - e a necessidade de sua determinação, pois o espírito não pode se afirmar senão ao se reconhecer como um ego (eu); o risco averroísta de uma universalidade do sujeito do pensamento adquirida ao preço da individualidade intelectual é descartada desde o início. Se o ego metafísico - esse núcleo residual assumido como fundamento - não cessa de nos fazer refletir sobre o enigma da consistência de sua identidade, graças a ele Descartes chega a conceber a universalidade da verdade como o fruto da responsabilidade individual, pois - e esta observação é, sem dúvida, capital - a estratégia meditativa sustenta uma decisão daquele que a adota (CANZIANI, 1999, p. 73).

Notemos, pois, que haveriam duas figuras da subjetividade: tomando o caráter biográfico da existência humana, de um lado o sujeito vivido, de uma vida prémeditativa em que a união da alma com o corpo é indiscernível. Por outro lado, como essência da primeira, as razões da metafísica mostra o ego como sujeito conhecedor, em que a vida e a metafísica teriam uma certa distância. Esta essência é descoberta de forma que o isolamento do sujeito, sem objetos, permite o aparecer de uma natureza metafísica que não quer se confundir com experiências particularizadas.

Notemos que no âmbito metafísico temos o ego cogitans como condição de toda 
experiência que possamos ter. Neste caso, foi este certo abandono da unidade psicossomática que permitiu ao ego não ser afetado pelo erro. É por isso que a via da análise é rigorosa nesta forma de proceder quanto à inventividade das descobertas da metafísica, enquanto que a partir destas a antropologia aparece como tratando do processo de individualização/particularização de uma natureza complexa, aquela do homem completo. Quanto ao tema, o intérprete alude à Carta de Elisabeth em que Descartes mostra haver duas coisas fundamentais da alma humana:

[...] uma é que eu penso, a outra, que estando unida ao corpo, ela pode agir e padecer com ele; eu não disse quase nada do último, e só a estou estudando para bem entender a primeira, porquê meu principal desejo era provar a distinção entre a alma e o corpo; que este último apenas pode servir, e o outro tinha sido prejudicado (DESCARTES, Carta à Elisabeth, o2-05-1643, AT, III, p. 664-665.).

A distinção real, segundo esta forma de interpretar a filosofia cartesiana, seria capital do ponto de vista metafísico e também do ponto de vista epistemológico. Demais, ela permitiria ir contra os hábitos mais sólidos próprios à vida comum. Distinta do corpo, a alma padece e age em conjunto com a parte somática. Se a união, como bem é demonstrado na Sexta Meditação, se revela por seus efeitos, a ação recíproca entre alma e o corpo aparece de forma capital no âmbito das afecções que se impõem à consciência.

Pensar a experiência pessoal foi uma das últimas empreitadas da filosofia cartesiana. Podemos observar que a correspondência com Elisabeth e o Tratado Paixões da Alma, estas obras retomam o âmbito sistêmico explicitado na Carta Prefácio à versão francesa dos Princípios da Filosofia. O estudo de Canziani contribui nesta discussão sobre a relação entre a metafísica e a vida, procurando mostrar as dificuldades de examinar a união substancial, conquanto ela trate da experiência da união no âmbito embrionário e dominado pelas quatro paixões primitivas.

Quanto ao tema, para prosseguir suas análises (CANZIANI, 1999, p. 78), o intérprete remete ao artigo 71 dos Princípios:

[...] durante os primeiros anos de nossa vida, [...]... nossa alma estava tão estritamente ligada ao corpo, que ela não se aplicava a outra coisa que o que lhe causou algumas impressões, ela ainda não considerava se estas impressões eram causadas pelas coisas que existiam fora dela (DESCARTES, Princípios, I, 71, AT, IX-2, p. 58).

Cabe observar o interessante processo de união da alma com o corpo em nível embrionário, pois ali a alma "não é capaz de distinguir o interior do exterior, para perceber o fato de que as impressões que ela recebe do corpo (a dor, o prazer, etc.) são causadas pelas coisas que existem fora" (CANZIANI, 1999, p. 79). Em carta a Chanut de $1^{\circ}$ de Fevereiro de 1647, o filósofo francês trataria desta experiência embrionária do homem, a qual seria dominada pelas paixões primitivas (a alegria, o amor, a tristeza, $\mathrm{o}$ 
ódio). Ocorre que a mistura e confusão do reino do sentimento, da união substancial, foi um dos temas mais atacados na filosofia cartesiana. De todo modo ultrapassar a dependência do corpo é um tema fundamental para Descartes, pois a distinção entre alma e corpo é muito bem mostrada como a condição para a fundação da teoria da alma e da física racional, sendo que a última visa não se embasar em qualidades reais e formas substanciais.

Canziani explica que na união substancial, sendo muito íntima a relação do espírito com a parte somática, muitas vezes o espírito falha ao utilizar os órgãos que lhe pertencem segundo a instituição da natureza, tornando difícil ou dificultoso distinguir o que seja espírito e o que seja extensão. O poder do corpo sobre o espírito, nas fases embrionária e durante a juventude, é de tal forma que nestas fases da vida de um homem os sentimentos são efeitos que expressam as funções do pensamento. O espírito estaria, pois velado, segundo as circunstâncias da biografia de cada indivíduo, pois toda experiência se lança sobre este nível antropológico da experiência da união. Então, ocorre que a descoberta de nossa alma se volta para discernir estes níveis essenciais da subjetividade. Neste caso, a ciência mecanicista e as razões da metafísica se complementam. Nas palavras do intérprete:

[...] a ciência mecanicista nos diz que a vida se explica em termos de matéria e movimento, e não é menos verdade que, para o sujeito concreto a experiência da vida, longe de se reduzir à pluralidade dos eventos materiais pelos quais ela se realiza, se traduz na unidade da consciência onde se sucedem continuamente os pensamentos racionais, as emoções e os impulsos, que deixam seus traços em sua memória e que influenciam suas atitudes. A disposição racional adquirida graças à metafísica é o fundamento último e o mais sólido sobre o qual se baseia nossa capacidade de controlar tanto quanto possível este fluxo de eventos, e de viver com liberdade os efeitos da ação recíproca entre o espírito e o corpo - efeitos que, mesmo quando eles são de origem puramente somática, tornam-se para cada um de nós os elementos de um processo de significação e de instituição de valores, que nós devemos saber decifrar e estimar (CANZIANI, 1999, p. $86-87$ ).

A discussão de Canziani perpassa en passant temas complexos ligados à união substancial, tais como a formação do indivíduo, a relação de Descartes com as formas substanciais e o problema da transubstanciação da Ostia. O artigo traz certas reflexões que permitem situar a discussão sobre os temas envolvidos, sem, evidentemente, propor esgotá-los, considerando a natureza do ensaio proposto. Se os estudos cartesianos muito se desenvolveu no século XX, sobretudo no que concerne à metafísica, isto se deu através de uma tradição que remonta a Hamelin, Laporte, Gilson e Gueroult. Por sua vez, os estudos cartesianos nas últimas duas décadas segue por explorar cuidadosamente terrenos menos investigados, tratando detalhadamente da moral e acerca da natureza do sujeito psicossomático, o que parece ser o caso do 
estudo de Canziani, acompanhando esta tendência muito bem representada por Guenancia, Kambouchner, entre outros.

\section{Referências}

DESCARTES, R. Euvres. Paris: Vrin, 1996. 11 vol. Publiées par Charles Adam et Paul Tannery, 1973-8.

GUENANCIA, P. Descartes. Tradução: Lucy Magalhães. Rio de Janeiro: Jorge Zahar Editor, 1991.

. Le corps peut-il être un sujet? In: Descartes et la question du sujet. Paris:

Presses Universitaires de France, 1999.

L'intelligence du sensible: essai sur le dualisme cartésien. França: Éditions

Gallimard, 1998.

GUEROULT, Martial. Descartes selon l'ordre des raisons. Paris: Aubier, 1968, vol. 2.

HAMELIN, Octave. El sistema de Descartes. Tradução de Amalia Haydée Raggio. Buenos Aires: Losada, 1949.

KAMBOUCHNER, Denis. L' Homme des passions: Commentaires sur Descartes. Paris: Albbin Michel, 1995. 2 t.

LAPORTE, J. Le rationalisme de Descartes. Paris: PUF, 1945.

ONG-VAN-KUNG K. (Org.). Descartes et la question du sujet. Paris: Presses Universitaires de France, 1999.

Submissão: 02.02.2017 / Aceite: 10.03.2017 